\title{
Evaluation of Transport Ventilators at Mild Simulated Altitude: A Bench Study in a Hypobaric Chamber
}

\author{
Salah Boussen MD PhD, Mathieu Coulange MD PhD, Marc Fournier MD, \\ Marc Gainnier MD PhD, Pierre Michelet MD PhD, Christophe Micoli, and Lionel Negrel
}

\begin{abstract}
BACKGROUND: Previous studies on ventilators used for air transport showed significant effects of altitude, in particular with regard to accuracy of the tidal volume $\left(V_{T}\right)$ and breathing frequency. The aim of the study was to evaluate transport ventilators under hypobaric conditions. METHODS: We conducted a bench study of 6 transport ventilators in a Comex hypobaric chamber to simulate mild altitude $(1,500 \mathrm{~m}[4,920$ feet $]$ and $2,500 \mathrm{~m}$ [8,200 feet]). The ventilators were connected to a test lung to evaluate their accuracy: (1) to deliver a set $V_{T}$ under normal resistance and compliance conditions at $\mathrm{F}_{\mathrm{IO}_{2}}=0.6$ and 1, (2) to establish a set PEEP $\left(0,5,10\right.$, and $15 \mathrm{~cm} \mathrm{H}_{2} \mathrm{O}$ ), and (3) to establish a set inspiratory pressure in pressure controlled mode, (4) at a $\mathrm{F}_{\mathrm{IO}_{2}}$ setting, and (5) and at a frequency setting. RESULTS: Four ventilators kept an average relative error in $V_{T}$ of $<10 \%$ without effect of altitude. The Medumat ventilator was affected by the altitude only at $\mathrm{F}_{\mathrm{OO}_{2}}=1$. The Osiris 3 ventilator had $>40 \%$ error even at $1,500 \mathrm{~m}$. We found no change in frequency as a function of altitude for any ventilators studied. No clinically important differences were found between all altitudes with the PEEP or inspiratory pressure setting. Although $\mathrm{F}_{\mathrm{IO}_{2}}$ was affected by altitude, the average error did not exceed $11 \%$, and it is unclear whether this fact is an experimental artifact. CONCLUSIONS: We have shown that most of the new transport ventilators tested require no setting adjustment at moderate altitude and are as safe at altitude as at sea level under normal respiratory conditions. Older technologies still deliver more volume with altitude in volumetric mode. Key words: ventilators; hypobaric chamber; altitude; bench study. [Respir Care 2014;59(8):1233-1241. (C) 2014 Daedalus Enterprises]
\end{abstract}

\section{Introduction}

Airlifting ventilated patients has become a daily routine for civilian and military emergency mobile services. Two vectors are used: helicopter and airplane. A helicopter is used for the extraction from a dangerous environment, for rapid response, and for regional transfers. This vector seems

Dr Boussen is affiliated with the Laboratoire de Biomécanique Appliquée, Aix Marseille Université, Marseille, France. Drs Boussen, Coulange, Fournier, Gainnier, and Michelet are affiliated with the Réanimation-Urgence-Samu-Hyperbarie Departement, Hôpital de la Timone, Marseille, France. Dr Coulange is also affiliated with Unité Mixte de Recherche MD2 "Dysoxie Tissulaire," Faculté de Médecine, Aix Marseille Université, Marseille, France. Mr Micoli and Mr Negrel are affiliated with Comex SA, Marseille, France.

Dr Michelet has previously consulted for Air Liquide Medical Systems without financial interest. Mr Micoli and Mr Negrel are employed by Comex SA. The other authors have disclosed no conflicts of interest. better suited than the road for unstable patients. ${ }^{1,2} \mathrm{~A}$ plane is used for transfers over longer distances. These 2 vectors impact the care of patients, especially critically ill patients. Recently, several teams have become specialized in transporting patients with ARDS or under extracorporeal circulation. ${ }^{3}$ The decrease in atmospheric pressure with altitude interferes with mechanical ventilation. ${ }^{4,5}$ Helicopter flights take place at altitudes of $<3,000 \mathrm{~m}$ and generally around $1,500 \mathrm{~m}$. During commercial or evacuation flights, the pressure of the aircraft cabin is usually set at a pressure corresponding to an altitude of $2,500 \mathrm{~m}$. Previous studies on ventilators used for air transport showed significant

\footnotetext{
Correspondence: Salah Boussen MD PhD, Laboratory of Biomechanics and Applications, Aix Marseille Université, IFSTTAR, LBA UMR_T 24, 13916 Marseille, France. E-mail: salah.boussen@ifsttar.fr.
}

DOI: $10.4187 /$ respcare. 02985 
effects of altitude, in particular with regard to accuracy of the tidal volume $\left(\mathrm{V}_{\mathrm{T}}\right)$ and breathing frequency. ${ }^{6-11}$ For some ventilators, an increase in $\mathrm{V}_{\mathrm{T}}$ of $>68 \%$ may lead to lung injuries. ${ }^{6}$ The next generation of ventilators showed that they were better adapted to the hypobaric environment, ${ }^{7}$ but with adaptations and some residual inaccuracies regarding $\mathrm{V}_{\mathrm{T}}$ delivery. Although new transport ventilators have emerged ${ }^{12}$ with improved performance compared with previous generations, it is unclear how a mild altitude affects performance of the new-generation ventilators. The aim of this bench study was to evaluate the accuracy of 6 recent transport ventilators in delivering the following adjustable parameters: $\mathrm{V}_{\mathrm{T}}$, PEEP, pressure (in pressure controlled mode), breathing frequency, and $\mathrm{F}_{\mathrm{IO}_{2}}$ under hypobaric conditions corresponding to mild simulated altitudes $(1,500 \mathrm{~m}[4,920$ feet $]$ and 2,500 m [8,200 feet]).

\section{Methods}

We tested 6 portable ventilators: Osiris 3 and Monnal T60 (Air Liquide Medical Systems, Paris, France), Oxylog 3000 and Carina (Dräger, Lübeck, Germany), Elisée 350 (ResMed, San Diego, California), and Medumat Transport with $\mathrm{CO}_{2}$ measure (WM 28400, Weinmann Medical Technology, Hamburg, Germany). The ventilators were provided by the manufacturers or were available in our hospital. Three of the tested ventilators are pneumatic (Oxylog 3000, Medumat, and Osiris 3), whereas the others are turbine. The Oxylog 3000, Monnal T60, Elisée 350, and Medumat are certified for operation in altitude by the manufacturers. These ventilators have pressure sensors. The atmospheric pressure range of use of these devices is as follows: Elisée 350, 500-1,100 hectopascals (hPa); Monnal T60, 600-1,150 hPa; Medumat, 540-1,100 hPa; and Oxylog, 570-1,200 hPa. The Carina does not have a pressure sensor. Its manufacturer guarantees normal functioning between 900 and $1,100 \mathrm{hPa}$ with restriction of flow and maximum pressure between 700 and $900 \mathrm{hPa}$. The Osiris 3 does not have a pressure sensor, and the operational atmospheric pressure range is not defined. The Osiris 3 was the oldest ventilator in the study.

The experimental setup was very similar to that used in previous studies. ${ }^{12-14}$ The ventilator to be tested was connected to a dual-chamber test lung (TTL 1600, Michigan Instruments, Grand Rapids, Michigan). The flow, pressure and $\mathrm{F}_{\mathrm{IO}_{2}}$ measurements were made using a pneumotachograph attached to a differential pressure transducer (TSD 160, Biopac Systems, Goleta, California), a differential pressure transducer ( $\pm 2.5 \mathrm{~cm} \mathrm{H}_{2} \mathrm{O}$; Biopac Systems) for air-flow measurement, a side port connected to a pressure transducer (TSD 104, -50 to $300 \mathrm{~cm} \mathrm{H}_{2} \mathrm{O}$; Biopac Systems) for pressure measurement, and an oxygen electrochemical sensor (CX0085, Comex SA, Marseille, France).

\section{QUICK LOOK}

\section{Current knowledge}

Ascent to altitude and a reduction in barometric pressure can impact movement of gases and volume of gases in a closed space. Mechanical ventilator performance at altitude can be similarly impacted and is often manifest by an increase in the delivered tidal volume.

\section{What this paper contributes to our knowledge}

A lung model evaluation of 6 portable ventilators (3 pneumatically controlled and 3 electronically controlled) in an altitude chamber to a barometric pressure of 8,200 feet demonstrated significant differences in delivered tidal volumes between devices. Pneumatic devices delivered significantly increased volumes compared with the set volume. No changes in breathing frequency, PEEP, or peak airway pressure were seen with any of the devices.

Before the experiment, the pneumotachograph and pressure transducer were calibrated at ground altitude with an ICU ventilator (PB840, Puritan Bennett, Pleasanton, California) operating under ambient temperature and dry pressure conditions. The flow transducer was calibrated with a constant flow in volume controlled mode. The calibration of the pneumotachograph was checked by measuring a known volume: we administered $2 \mathrm{~L}$ of air through the pneumotachograph via a $2-\mathrm{L}$ super syringe. There was $<1 \%$ discrepancy. The pressure transducer was calibrated with the PB840 at 0 and a PEEP of $10 \mathrm{~cm} \mathrm{H}_{2} \mathrm{O}$. During the experiments, the flow and pressure signals were acquired with an analog digital converter (MP100, Biopac Systems). The volume was obtained by integrating the flow signal. The acquisition frequency of all signals was set at $200 \mathrm{~Hz}$. All data were stored in a computer for subsequent analysis (AcqKnowledge software, Biopac Systems).

The experiments were conducted on Comex SA premises using a Comex $\mathrm{C} 2400$ chamber $\left(35 \mathrm{~m}^{2}\right)$. For the purpose of safety, the ambient oxygen level was actively maintained below $23 \%$ by ventilating the chamber. An electrochemical sensor (Comex CX0043) measured the oxygen level continuously. In addition to the ground altitude, we simulated altitudes of 1,500 and $2,500 \mathrm{~m}$. To simulate altitude, the pressure was lowered in the hypobaric chamber. The pressure was set to $835 \mathrm{hPa}$ and then to $745 \mathrm{hPa}$. These pressures correspond to respective altitudes of $1,500 \mathrm{~m}$ (4,920 feet) and $745 \mathrm{hPa}(8,200$ feet $)$ according to standard atmosphere defined by the International Civil Aviation Organization. The average cabin pressure of jetliners and medical evacuation planes is $745 \mathrm{hPa}$, which is equiv- 
alent to an altitude of 2,500 $\mathrm{m}(8,200$ feet). This value can slightly change with the type of airplane.

\section{Protocol}

The performances were assessed with the test lung connected to the ventilator tested. The parameters were set to normal respiratory mechanics with a normal airway resistance $\left(5 \mathrm{~cm} \mathrm{H}_{2} \mathrm{O} / \mathrm{L} / \mathrm{s}\right)$ and lung compliance (100 $\mathrm{mL} / \mathrm{cm} \mathrm{H}_{2} \mathrm{O}$ ). The resistance was achieved with a parabolic resistor (Pneuflo Rp5, Michigan Instruments), and the compliance was set on the test lung. All ventilators were operated according to the manufacturers' instructions, taking into account the circuit compliance correction algorithm when it was available.

The following experiments were performed at ground and simulated altitudes of 1,500 and 2,500 m, respectively.

\section{$\mathbf{V}_{\mathrm{T}}$ Delivery}

For all ventilators tested, the breathing frequency (f) was set at 12 breaths/min, and the inspiratory time $\left(\mathrm{T}_{\mathrm{I}}\right)$ was 1 s. All ventilators were operated at a PEEP of $5 \mathrm{~cm} \mathrm{H}_{2} \mathrm{O} . \mathrm{V}_{\mathrm{T}}$ values of 300,500 , and $800 \mathrm{~mL}$ were set for each ventilator. The measured $\mathrm{V}_{\mathrm{T}}$ values were averaged over 5 breaths after stabilization. We performed the measurements at $\mathrm{F}_{\mathrm{IO}_{2}}=0.6$ and 1, except with the Osiris 3, which does not allow 0.6 but instead uses an undefined air-oxygen mixture.

We computed the relative error for each $\mathrm{V}_{\mathrm{T}}$ : $100 \times$ $\left(\left(\right.\right.$ measured $\mathrm{V}_{\mathrm{T}}-$ set $\left.\mathrm{V}_{\mathrm{T}}\right)$ /set $\left.\mathrm{V}_{\mathrm{T}}\right)$. For each altitude and $\mathrm{F}_{\mathrm{IO}_{2}}$, we averaged the error over $\mathrm{V}_{\mathrm{T}}$ values of 300,500 , and $800 \mathrm{~mL}$.

\section{Breathing Frequency and PEEP Measurements}

For measurements of PEEP and breathing frequency, the setting parameters were: $\mathrm{V}_{\mathrm{T}}=500 \mathrm{~mL}, \mathrm{~T}_{\mathrm{I}}=1 \mathrm{~s}$, $\mathrm{f}=12$ breaths $/ \mathrm{min}$, and $\mathrm{F}_{\mathrm{IO}_{2}}=0.6$ (air-oxygen mixture for the Osiris 3).

We averaged the time between 5 consecutives breaths at steady state and then calculated the frequency. PEEP was set at $0,5,10$, and $15 \mathrm{~cm} \mathrm{H}_{2} \mathrm{O}$, except for the Carina, which does not allow zero PEEP. We computed the relative error for each PEEP. The error was averaged for the 4 (or 3) PEEP levels.

\section{Pressure Accuracy}

We tested the pressure accuracy in pressure controlled mode for all ventilators, except for the Osiris 3, which does not have this mode. $\mathrm{F}_{\mathrm{IO}_{2}}$ was set at 0.6 , with $\mathrm{f}=12$ breaths $/ \mathrm{min}, \mathrm{T}_{\mathrm{I}}=1 \mathrm{~s}$, and PEEP $=5 \mathrm{~cm} \mathrm{H}_{2} \mathrm{O}$. The inspiratory pressure (defined as the absolute pressure over the PEEP) was set at $10,15,20$, and $25 \mathrm{~cm} \mathrm{H}_{2} \mathrm{O}$. Pressures were measured for 5 consecutive breaths after stabilization. We computed the relative error for each pressure, and the error was averaged for the 4 levels of pressure.

\section{$\mathrm{F}_{\mathrm{IO}_{2}}$ Accuracy}

The ventilators were set as follow: $\mathrm{V}_{\mathrm{T}}=500 \mathrm{~mL}, \mathrm{f}=$ 20 breaths $/ \mathrm{min}$, and inspiratory-expiratory ratio $=1: 2$. The $\mathrm{F}_{\mathrm{IO}_{2}}$ was varied between 0.21 and $1: 0.21-0.4-0.6-1$ for the Elisée 350, Monnal T60, and Carina; 0.4-0.6-1 for the Medumat and Oxylog 3000; and air/oxygen mixture and 1 for the Osiris 3. We computed the average error for the 4 or 3 set $\mathrm{F}_{\mathrm{IO}_{2}}$ values.

\section{Statistical Analysis}

Each variable value represents the mean of values measured at steady state. For $\mathrm{V}_{\mathrm{T}}$, PEEP, breathing frequency, and pressure accuracy measurements, we considered the mean of 5 consecutive breaths at steady state. All results were expressed as the mean \pm SD. For comparative analysis, we used a one-way analysis of variance on ranks (Kruskal-Wallis test). $P<.05$ was considered statistically significant. However, metrology measurements are very precise and lead to situations in which differences are always significant. Instead, we considered a clinically important difference to be when the difference between the set and measured parameters exceeded $10 \%$. We did so to comply with the standard of ASTM International, where the $\mathrm{V}_{\mathrm{T}}$ should be $\pm 10 \%$ of the nominal volume. ${ }^{15}$ For our statistical analysis, we used SigmaStat 3.5 (SPSS, Chicago, Illinois)

\section{Ethical Issues}

Two volunteer operators conducted the experiments. Both simulated altitudes do not require oxygen in the international regulation of aeronautics. The volunteers' health was considered compatible with the relative deprivation of oxygen after medical examination. The oxygen content of the hypobaric chamber was controlled strictly to avoid the risk of explosion in a confined space.

\section{Results}

\section{Hypobaric Conditions}

At a simulated altitude of $2,500 \mathrm{~m}$, the pressure was $745 \pm 5 \mathrm{hPa}$, the temperature was $21^{\circ} \mathrm{C}$, and $\mathrm{P}_{\mathrm{O}_{2}}$ was actively maintained between 160 and $170 \mathrm{ppm}$, corresponding to $\mathrm{F}_{\mathrm{IO}_{2}}$ values of 0.215 and 0.22 . 

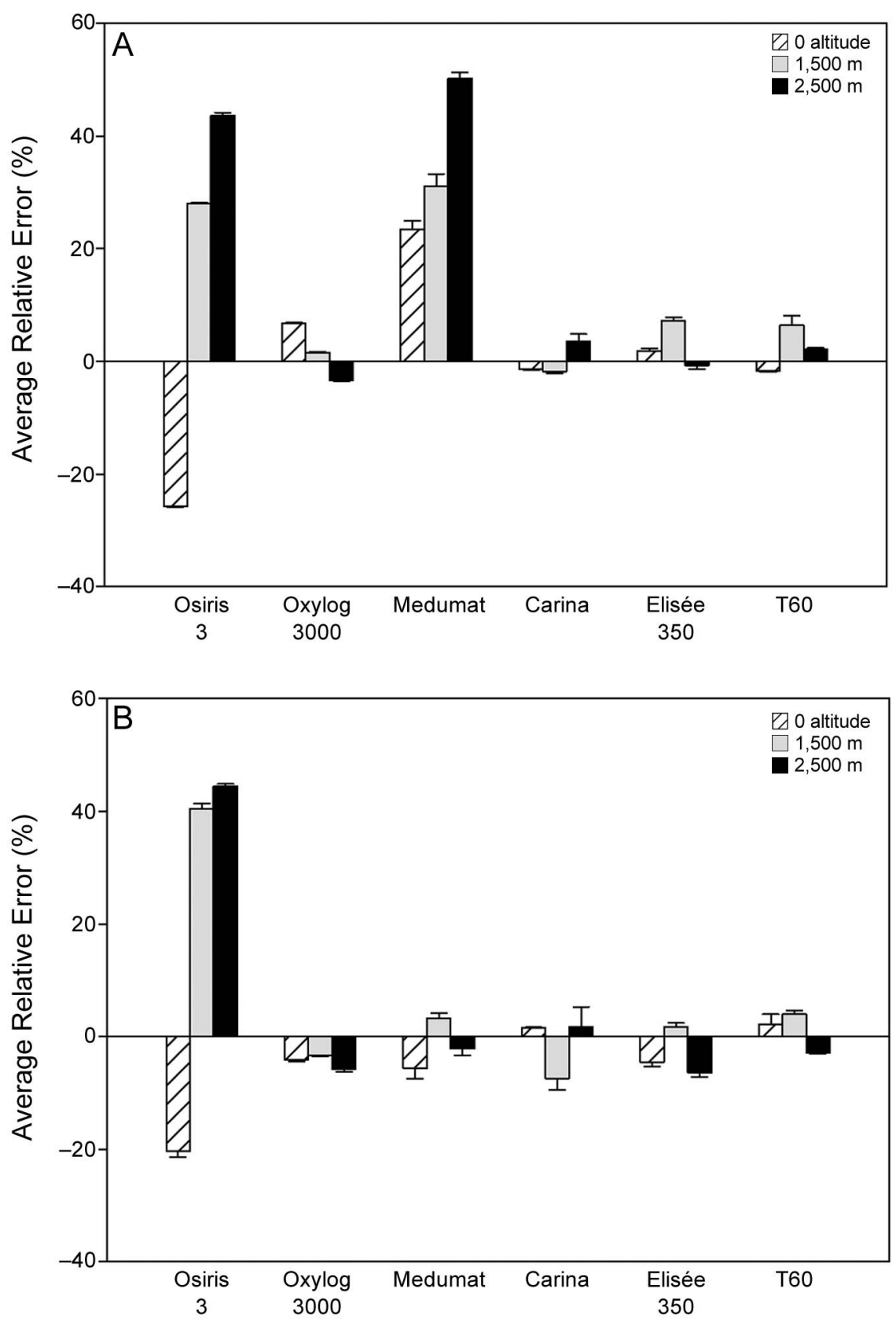

Fig. 1. Average relative error of tidal volume for the 3 altitudes. $A: F_{\mathrm{IO}_{2}}=1$. B: $\mathrm{F}_{\mathrm{IO}_{2}}=0.6$.

At a simulated altitude of $1,500 \mathrm{~m}$, the pressure was between 835 and $840 \mathrm{hPa}$ with a $\mathrm{P}_{\mathrm{O}_{2}}$ of $180-190 \mathrm{ppm}$, corresponding to a $\mathrm{F}_{\mathrm{IO}_{2}}$ of $0.22-0.23$.

\section{$\mathbf{V}_{T}$ Delivery}

Figure 1 shows the relative errors as a percentage of the $\mathrm{V}_{\mathrm{T}}$ for 3 altitude levels for each individual ventilator at 2 set $\mathrm{F}_{\mathrm{IO}_{2}}$ values, 0.6 and 1 . Table 1 lists the $\mathrm{V}_{\mathrm{T}}$ average error ranges for all considered $\mathrm{F}_{\mathrm{IO}_{2}}$ and $\mathrm{V}_{\mathrm{T}}$ values and altitudes. At $\mathrm{F}_{\mathrm{IO}_{2}}=0.6$, there was no change with respect to the altitude, and the errors remained below $10 \%$ for all ventilators, excluding the Osiris 3.

At $\mathrm{F}_{\mathrm{IO}_{2}}=1$ for all ventilators, excluding the Osiris 3 and Medumat, there was no change with respect to altitude, and the errors remained below $7 \%$ for all ventilators. The Medumat did not perform well when tested at $\mathrm{F}_{\mathrm{IO}_{2}}=1$, all $\mathrm{V}_{\mathrm{T}}$ values were greater than the set $\mathrm{V}_{\mathrm{T}}$, and the error grew linearly with altitude. This dysfunction began at sea level. The Osiris 3 had the same dysfunction at 1,500 and 
Table 1. $\mathrm{V}_{\mathrm{T}}$ Measurements

\begin{tabular}{|c|c|c|}
\hline $\mathrm{V}_{\mathrm{T}}$ & $\begin{array}{l}\text { Error Range } \\
(\%)^{*}\end{array}$ & $\begin{array}{c}\text { Median } \\
(\%)^{*}\end{array}$ \\
\hline \multicolumn{3}{|c|}{$\mathrm{F}_{\mathrm{IO}_{2}}=0.6$} \\
\hline \multicolumn{3}{|c|}{ Altitude of $0 \mathrm{~m}$} \\
\hline $300 \mathrm{~mL}$ & 7.5 to 9.5 & -5.5 \\
\hline $500 \mathrm{~mL}$ & -7 to 4 & -5 \\
\hline $800 \mathrm{~mL}$ & -4.5 to 2 & -2 \\
\hline \multicolumn{3}{|c|}{ Altitude of $1,500 \mathrm{~m}$} \\
\hline $300 \mathrm{~mL}$ & -5.5 to 62 & 1 \\
\hline $500 \mathrm{~mL}$ & -12.5 to 36 & -12.5 \\
\hline $800 \mathrm{~mL}$ & -4.5 to 23.5 & 2 \\
\hline \multicolumn{3}{|c|}{ Altitude of $3,000 \mathrm{~m}$} \\
\hline $300 \mathrm{~mL}$ & -12.5 to 68 & -7.5 \\
\hline $500 \mathrm{~mL}$ & -5.5 to 35 & -1 \\
\hline $800 \mathrm{~mL}$ & -3 to 30 & 0 \\
\hline \multicolumn{3}{|c|}{$\mathrm{F}_{\mathrm{IO}_{2}}=1$} \\
\hline \multicolumn{3}{|c|}{ Altitude of $0 \mathrm{~m}$} \\
\hline $300 \mathrm{~mL}$ & -13.5 to 26.5 & 0.5 \\
\hline $500 \mathrm{~mL}$ & -13 to 24 & 4 \\
\hline $800 \mathrm{~mL}$ & -13 to 19.5 & 5.5 \\
\hline \multicolumn{3}{|c|}{ Altitude of $1,500 \mathrm{~m}$} \\
\hline $300 \mathrm{~mL}$ & $0-38.5$ & 7.5 \\
\hline $500 \mathrm{~mL}$ & -3 to 29 & 6.5 \\
\hline $800 \mathrm{~mL}$ & -4.5 to 28.5 & 4 \\
\hline \multicolumn{3}{|c|}{ Altitude of $3,000 \mathrm{~m}$} \\
\hline $300 \mathrm{~mL}$ & -6.5 to 60.5 & -0.5 \\
\hline $500 \mathrm{~mL}$ & -5.5 to 99 & 4 \\
\hline $800 \mathrm{~mL}$ & 2-37.5 & 5 \\
\hline
\end{tabular}

2,500 $\mathrm{m}$ at both $\mathrm{F}_{\mathrm{IO}_{2}}$ settings, but with normal functioning at sea level (without a significant difference between $\mathrm{F}_{\mathrm{IO}_{2}}=1$ and air-oxygen mixture).

\section{Breathing Frequency and PEEP Accuracy}

We found no change in frequency as a function of altitude for all ventilators studied.

Table 2 lists the average PEEP error as a percentage for the different altitudes. No significant differences were found at a relevant clinical level between all altitudes. The error remained well under $10 \%$. At a PEEP of $15 \mathrm{~cm} \mathrm{H}_{2} \mathrm{O}$, an error of $10 \%$ represents $1.5 \mathrm{~cm} \mathrm{H}_{2} \mathrm{O}$. Figure 2 shows the results of the experiments for each individual ventilator.

\section{Pressure Accuracy}

Figure 3 shows the results of the pressure accuracy experiments. The average errors in percentage ranges are listed in Table 2. No significant differences were found at a relevant clinical level between all altitudes for all ven-
Table 2. PEEP, Pressure Accuracy, and $\mathrm{F}_{\mathrm{IO}_{2}}$ Measurements

\begin{tabular}{lrr}
\hline \hline & $\begin{array}{c}\text { Error Range } \\
(\%)^{*}\end{array}$ & $\begin{array}{r}\text { Median } \\
(\%)^{*}\end{array}$ \\
\hline PEEP & -3.3 to 5.8 & 0.1 \\
Altitude of $0 \mathrm{~m}$ & -5 to 3.5 & -1.1 \\
Altitude of $1,500 \mathrm{~m}$ & -2.7 to 4.1 & -1.1 \\
Altitude of $2,500 \mathrm{~m}$ & & \\
Pressure accuracy & -2.1 to 3.9 & 1.0 \\
Altitude of $0 \mathrm{~m}$ & -2.2 to 6.9 & 4.4 \\
Altitude of $1,500 \mathrm{~m}$ & -1.3 to 6.0 & 4.4 \\
Altitude of $2,500 \mathrm{~m}$ & & 2.1 \\
$\mathrm{~F}_{\mathrm{IO}_{2}}$ accuracy & $0.5-10.9$ & 7.2 \\
Altitude of $0 \mathrm{~m}$ & $3.8-10.8$ & 7.4 \\
Altitude of $1,500 \mathrm{~m}$ & $2.7-11.2$ & \\
Altitude of $2,500 \mathrm{~m}$ & & \\
\hline & & \\
\hline Relative to target volume & & \\
\hline
\end{tabular}

tilators. We did not find any $\mathrm{V}_{\mathrm{T}}$ changes with altitude, although $V_{T}$ values were different with the ventilators.

\section{$\mathrm{F}_{\mathrm{IO}_{2}}$ Accuracy}

Figure 4 shows the results of the $\mathrm{F}_{\mathrm{IO}_{2}}$ experiments. The average errors in percentage ranges are listed in Table 2. None of the ventilators had $>3 \%$ error at $100 \%$, so errors were always $<5 \%$ at the $\mathrm{F}_{\mathrm{IO}_{2}}$ setting. We did find a significant increase in error with respect to altitude with almost all ventilators. However, the average relative error in $\mathrm{F}_{\mathrm{IO}_{2}}$ was still $<11 \%$.

\section{Discussion}

There are only a few studies on ventilators under hypobaric conditions due to technical difficulties (availability of hypobaric chambers) or experimental costs (plane or helicopter tests). Early studies showed that older-generation pneumatic ventilators did not properly deliver the set $\mathrm{V}_{\mathrm{T}}$ even at moderate altitudes. ${ }^{6,10,16,17}$ These ventilators are still widely used and are stockpiled for potential use in a pandemic. Studies showed that these devices are inaccurate in delivering volumes even at ground altitude. ${ }^{18,19}$ Our study included only one ventilator of this type, the Osiris 3 . We found the same type of dysfunction. The Osiris 3 delivers a $V_{T}$ with an error of $>40 \%$ even at mild altitude. This type of ventilator should be avoided for air transport. However, they are less expensive than the new generation of ventilators and are still widely used in air transport.

Studies on more recent ventilators show that they are able to manage altitude without major dysfunction (Impact agle 754 [Impact Instrumentation, West Caldwell, New Jersey], LTV 1000 [CareFusion, San Diego, California], Oxylog 3000, and Elisée 350). The T-Bird VS02 must be compen- 


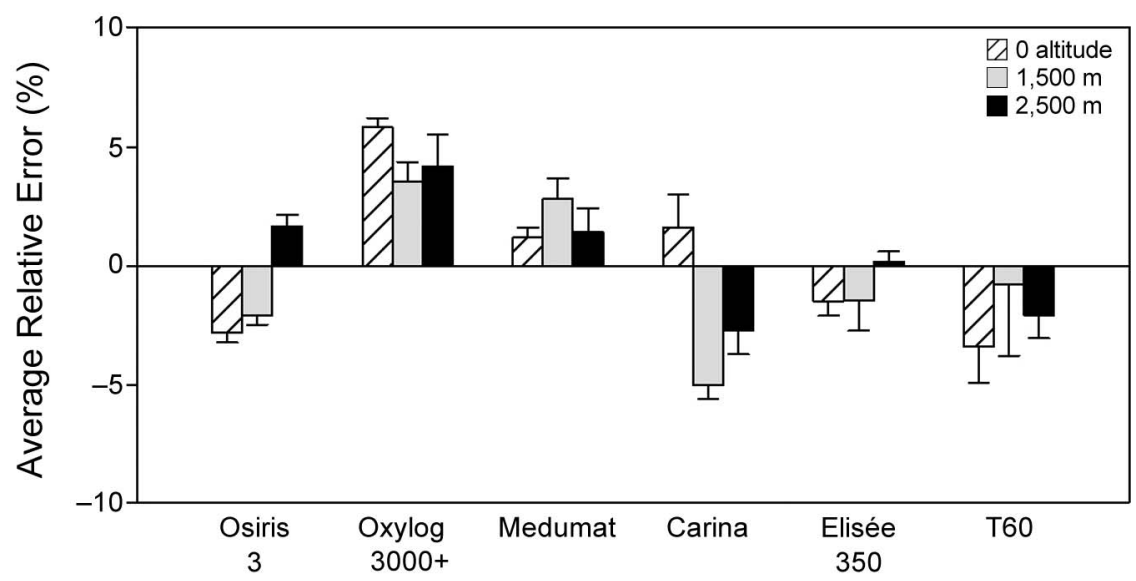

Fig. 2. Mean values of the average error made in PEEP for the 3 altitudes. Note that the scale is enlarged and that the errors are $<10 \%$ for all ventilators.

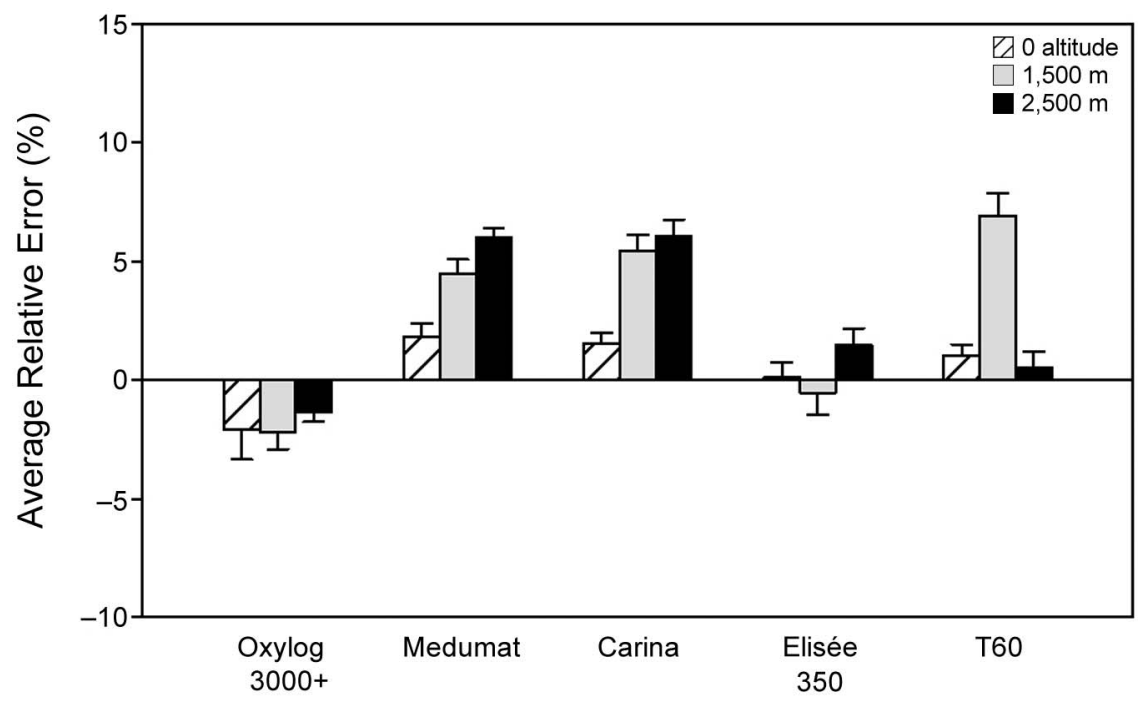

Fig. 3. Mean values of the average error of inspiratory pressure for the 3 altitudes.

sated manually, and the LTV 1000 has a drift with increasing altitude of $>10 \% .^{7}$ Many of these ventilators are turbinedriven. A turbine provides the pressurization and gas flow. Its operation is affected by a reduction in ambient pressure: at altitude, air is less dense, and the rotating turbine therefore compresses less air. Recent ventilators have atmospheric pressure sensors to compensate for this effect (Monnal T60, Oxy$\log$ 3000, Elisée 350, Impact Eagle 754, and Medumat). We confirm that new-generation ventilators do not have major performance changes at mild altitude, even non-approved ventilators for air transport such as the Carina. In our study, the Oxylog 3000, Elisée 350, Monnal T60, and Carina did not produce any clinically important differences in $\mathrm{V}_{\mathrm{T}}$ on the ground or at altitude and required no adjustment to maintain a constant $\mathrm{V}_{\mathrm{T}}$. It seems that taking into account the ambient pressure sensor can properly correct the effects of altitude. The Carina does not have a pressure sensor and was accurate in volume delivery in the range of pressures we investigated. It is possible that turbine-driven ventilators are not very sensitive to mild altitude changes. However, the Carina does have a restriction in flow and maximum pressure between 700 and $900 \mathrm{hPa}$. This limitation was not significant here, as we investigated a highly compliant lung and normal airway resistance. A previous study found that the LTV 1000 had $10 \%$ increases at 10,000 feet $(3,300 \mathrm{~m}) .^{7}$ The LTV 1000 is a turbine-driven ventilator without a pressure sensor or altitude compensation such as the Carina and is used by the United States Air Force Critical Care Air Transport Team.

Operation is simplified compared with the T-Bird VS02 since compensation is automatic and does not require any particular intervention. The Oxylog 3000 is a gas-powered ventilator, provides an automatic compensation for altitude, and is not affected at mild altitude. The Medumat is different; this ventilator is guaranteed for altitude opera- 


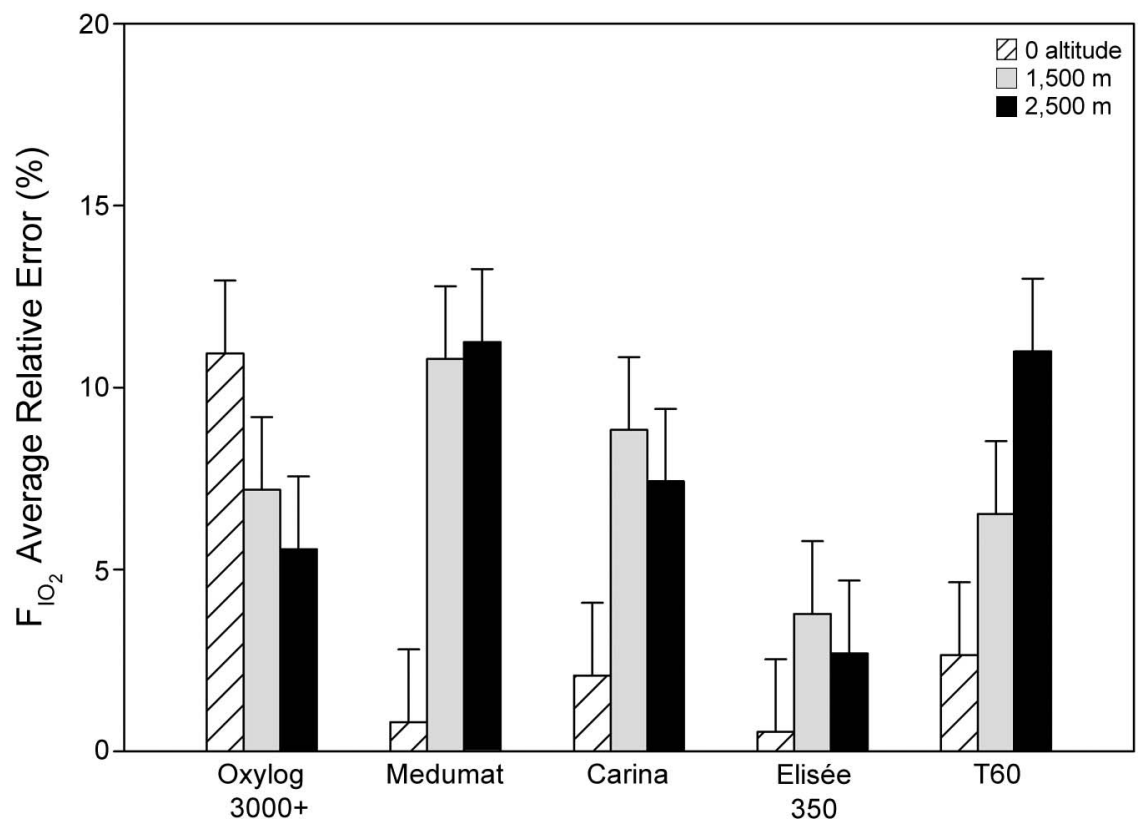

Fig. 4. Mean values of the average error made in $\mathrm{F}_{\mathrm{IO}_{2}}$ for the 3 altitudes.

tion by the manufacturer, works correctly at $\mathrm{F}_{\mathrm{IO}_{2}}=0.6$, and shows no alteration at altitude. However, at $\mathrm{F}_{\mathrm{IO}_{2}}=1$, it has a major $\mathrm{V}_{\mathrm{T}}$ error of $>20 \%$ at sea level altitude, and this error grows with altitude. Figure 5 shows the flow waveform of the Medumat at $\mathrm{F}_{\mathrm{IO}_{2}}=0.6$ and 1. It is clear that the pneumatic valve has a different behavior with the $\mathrm{F}_{\mathrm{IO}_{2}}$ setting. At $\mathrm{F}_{\mathrm{IO}_{2}}=1$, the valve lets too much gas enter the early part of the insufflation, and then the algorithm attempts to stabilize the flow. It seems that during the flow overshoot, the amount of gas is not controlled by the ventilator and is not taken in account by the algorithm for calculation of the $\mathrm{V}_{\mathrm{T}}$. This error grows in magnitude with altitude. $\mathrm{F}_{\mathrm{IO}_{2}}$ effect on $\mathrm{V}_{\mathrm{T}}$ accuracy had been shown already in pneumatic ventilators but with high airway resistive load $20: \mathrm{V}_{\mathrm{T}}$ was found to be $30 \%$ lower than the $\mathrm{V}_{\mathrm{T}}$ set at $\mathrm{F}_{\mathrm{IO}_{2}}=0.6$. This was not what we observed for the Medumat, which had an increase in $\mathrm{V}_{\mathrm{T}}>30 \%$ at $\mathrm{F}_{\mathrm{IO}_{2}}=1$.

We did not show any change in frequency with altitude, as was observed in older ventilators. ${ }^{6}$ All ventilators precisely delivered PEEP and inspiratory pressure in pressure controlled mode when available. This shows that their airway pressure sensors functioned without alteration at moderate altitudes. No adjustment should be made in the pressure setting at varying altitudes. We propose to use pressure controlled modes instead of volume controlled modes for pneumatic ventilators without altitude compensation. Unfortunately, this mode is not always available on these ventilators, such as Osiris 3. Although we did not observed volume changes with altitude in pressure mode, we did not study the volume measurement accuracy of the ventilators. Because volume monitoring is important in pressure mode, further studies are necessary.

We did not show clinically relevant errors in delivering the set $\mathrm{F}_{\mathrm{IO}_{2}}$. However, $\mathrm{F}_{\mathrm{IO}_{2}}$ seemed to change with altitude in our measurements. We attribute this phenomenon to the measurement itself. Indeed, the $\mathrm{F}_{\mathrm{IO}_{2}}$ sensor used measures the $\mathrm{P}_{\mathrm{O}_{2}}$. In the chamber, $\mathrm{P}_{\mathrm{O}_{2}}$ is subject to slight total ambient pressure change and air pollution by the rejected oxygen (1-2 points $\mathrm{F}_{\mathrm{IO}_{2}}$ ), leading to errors at the same level as the one measured. However, the observed variation in $\mathrm{F}_{\mathrm{IO}_{2}}$ remains weak and is not clinically relevant.

The limitations of this study are similar to those performed in a bench test. ${ }^{12-14}$ Concerning the aeronautical environment, we did not reproduce the vibrations that could disrupt the turbines of some ventilators. However, tests under real conditions would be more expensive, and these ventilators are already used in harsh environments such as ambulances. We have not tested at simulated higher altitudes because these operations are rare (mountain rescue or exfiltration in a war zone). Additionally, in this study, we investigated only a highly compliant lung and normal airway resistance.

\section{Conclusion}

In conclusion, we have shown that most of the new ventilators require no setting adjustments at moderate altitude and that they are as safe at altitude as at sea level under normal respiratory conditions. However, we must remain cautious regarding certain new ventilators (such as 

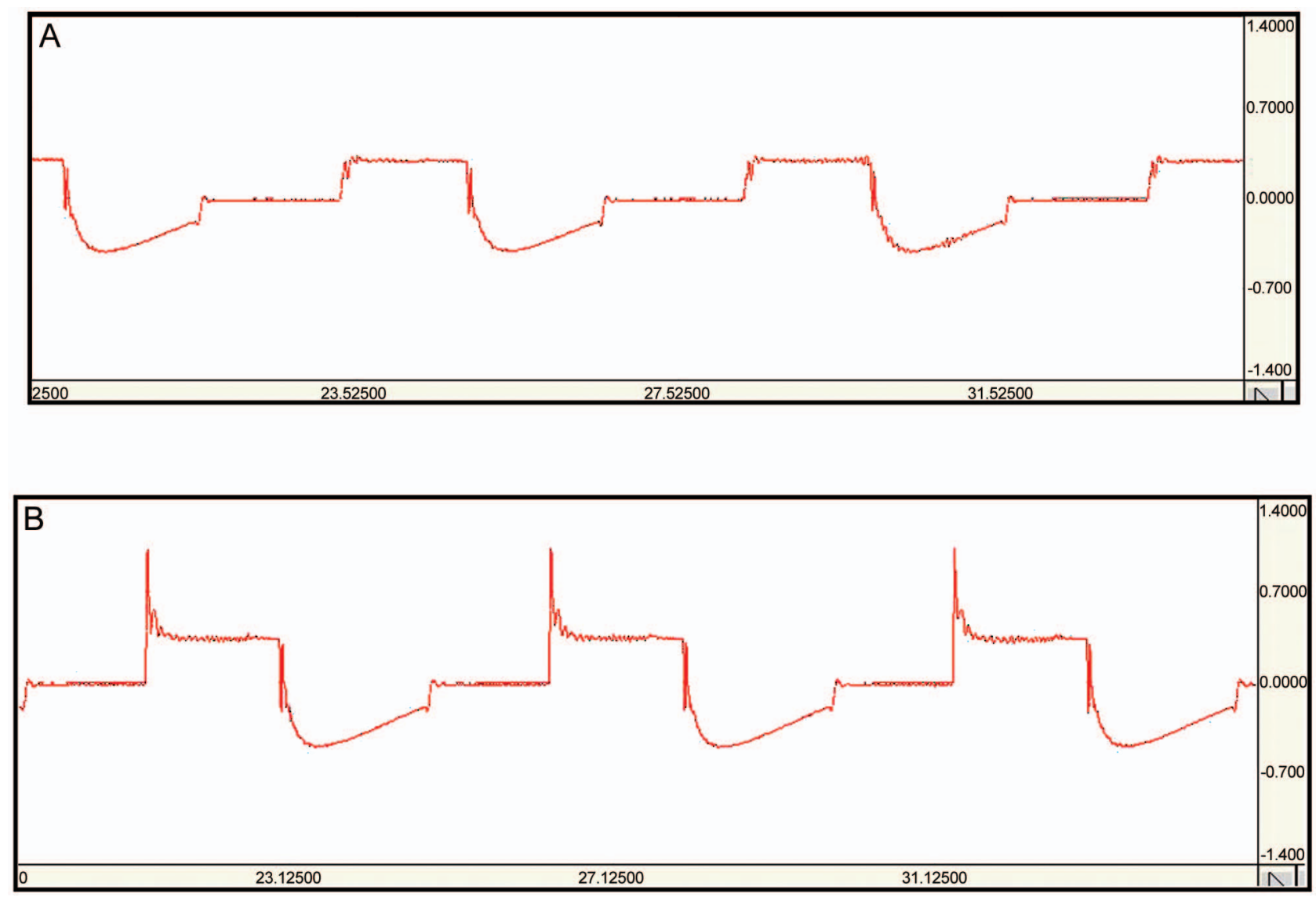

Fig. 5. Flow waveform of Medumat. $A: F_{1 O_{2}}=0.6$. B: $F_{1 O_{2}}=1$. The valve has a malfunction inducing a higher $V_{T}$ at $F_{1 O_{2}}=1$ than the set $V_{T}$. This pattern was found for all settings. The 2 waveforms were recorded at zero altitude with a set $V_{T}$ of $500 \mathrm{~mL}$.

the Medumat) at $\mathrm{F}_{\mathrm{IO}_{2}}=1$ or older ventilators (such as the Osiris 3). On the other hand, we also showed that only the $\mathrm{V}_{\mathrm{T}}$ is impacted by altitude operation. Clinicians should be aware of the limitations of the ventilator they use, as $\mathrm{V}_{\mathrm{T}}$ plays a very important part in lung protection.

\section{ACKNOWLEDGMENTS}

We are grateful to Dani Marino for assistance with editing.

\section{REFERENCES}

1. Andruszkow H, Lefering R, Frink M, Mommsen P, Zeckey C, Rahe $\mathrm{K}$, et al. Survival benefit of helicopter emergency medical services compared to ground emergency medical services in traumatized patients. Crit Care 2013;17(3):R124.

2. Sullivent EE, Faul M, Wald MM. Reduced mortality in injured adults transported by helicopter emergency medical services. Prehosp Emerg Care 2011;15(3):295-302.

3. Dorlac GR, Fang R, Pruitt VM, Marco PA, Stewart HM, Barnes SL, Dorlac, WC. Air transport of patients with severe lung injury: development and utilization of the Acute Lung Rescue Team. J Trauma 2009;66(4 Suppl):S164-S171.

4. Farmer JC. Respiratory issues in aeromedical patient transport. Respir Care Clin N Am 1996;2(3):391-400.
5. Tourtier JP, Franck L, Cirodde A, Coste S, Debien B. Flight ventilation and Boyle-Mariotte law. Resuscitation 2011;82(8):1112.

6. Flynn JG, Singh B. The performance of Dräger Oxylog ventilators at simulated altitude. Anaesth Intensive Care 2008;36(4):549-552.

7. Rodriquez D Jr, Branson RD, Dorlac W, Dorlac G, Barnes SA, Johannigman JA. Effects of simulated altitude on ventilator performance. J Trauma 2009;66(4 Suppl):S172-S177.

8. Tourtier JP, Libert N, Leclerc T, Borne M. Effects of simulated altitude on ventilator performance: interest of acute respiratory distress syndrome and asthma lung models. J Trauma 2010;68(3):749750 .

9. Roeggla M. Mechanical ventilation at moderate altitude. Anaesth Intensive Care 1995;23(4):515-516.

10. Kirby RR, DiGiovanni AJ, Bancroft RW, McIver RG. Function of the Bird respirator at high altitude. Aerosp Med 1969;40(5):463-469.

11. Tourtier JP, Leclerc T, Cirodde A, Libert N, Man M, Borne M. Acute respiratory distress syndrome: performance of ventilator at simulated altitude. J Trauma 2010;69(6):1574-1577.

12. Boussen S, Gainnier M, Michelet P. Evaluation of ventilators used during transport of critically ill patients: a bench study. Respir Care 2013;58(11):1911-1922.

13. Zanetta G, Robert D, Guérin C. Evaluation of ventilators used during transport of ICU patients-a bench study. Intensive Care Med 2002; 28(4):443-451.

14. Lyazidi A, Thille AW, Carteaux G, Galia F, Brochard L, Richard JC. Bench test evaluation of volume delivered by modern ICU ventila- 


\section{Transport Ventilators at Simulated Altitude}

tors during volume-controlled ventilation. Intensive Care Med 2010; 36(12):2074-2080.

15. Bruckart JE, Licina JR, Quattlebaum M. Laboratory and flight tests of medical equipment for use in U.S. Army Medevac helicopters. Air Med J 1993;1(3):51-56.

16. Roeggla M, Roeggla G, Wagner A, Eder B, Laggner AN. Emergency mechanical ventilation at moderate altitude. Wilderness Environ Med 1995;6(3):283-287.

17. Thomas G, Brimacombe J. Function of the Drager Oxylog ventilator at high altitude. Anaesth Intensive Care 1994;22(3):276-280.
18. L'Her E, Roy A. Bench tests of simple, handy ventilators for pandemics: performance, autonomy, and ergonomy. Respir Care 2011; 56(6):751-760

19. McGough EK, Banner MJ, Melker RJ. Variations in tidal volume with portable transport ventilators. Respir Care 1992;37(3):233239 .

20. Breton L, Minaret G, Aboab J, Richard JC. Fractional inspired oxygen on transport ventilators: an important determinant of volume delivery during assist control ventilation with high resistive load. Intensive Care Med 2002;28(8):1182. 